\title{
Is rifampin use associated with better outcome in staphylococcal prosthetic valve endocarditis? A multicenter retrospective study
}

Audrey Le Bot ${ }^{1}$, Raphaël Lecomte ${ }^{2}$, Pierre Gazeau ${ }^{3}$, François Benezit ${ }^{1}$, Cédric Arvieux ${ }^{1}$, Séverine Ansart ${ }^{3}$, David Boutoille ${ }^{2}$, Rozenn Le Berre ${ }^{4}$, Céline Chabanne ${ }^{5}$, Matthieu Lesouhaitier $^{1}$, Loren Dejoies ${ }^{6,8}$, Erwan Flecher $^{5}$, Jean-Marc Chapplain ${ }^{1}$, Pierre Tattevin ${ }^{1,7,8}$, Matthieu Revest ${ }^{1,7,8}$ pour le Groupe d'Epidémiologie et Recherche en Infectiologie du Centre et de l'Ouest (GERICCO)

${ }^{1}$ Infectious Diseases and Intensive Care Unit, Pontchaillou University Hospital, Rennes, France; ${ }^{2}$ Department of Infectious Diseases, CIC UIC 1413 INSERM, University Hospital,, Nantes, France; ${ }^{3}$ Infectious Diseases and Tropical Medicine, La Cavale Blanche University Hospital, Brest, France; ${ }^{4}$ Department of Internal Medecine and pneumology, La Cavale Blanche University Hospital, Brest, France; ${ }^{5}$ Department of thoracic and cardiovascular surgery, Pontchaillou University Hospital, Rennes, France; ${ }^{6}$ Department of bacteriology, Pontchaillou University Hospital, Rennes, France; ${ }^{7}$ CIC-Inserm 1414, Pontchaillou University Hospital, Rennes, France; ${ }^{8}$ University of Rennes, Inserm, BRM (Bacterial Regulatory RNAs and Medicine), UMR_1230, France

Corresponding author: Pierre Tattevin, Infectious Diseases and Intensive Care Unit, Pontchaillou University Hospital, 2, rue Henri Le Guilloux, 35033 Rennes Cedex 9, France. Phone: +33 299289564. ORCID: 0000-0003-3617-5411. E-mail: pierre.tattevin@chu$\underline{\text { rennes.fr }}$

Alternate corresponding author: Matthieu Revest. E-mail: matthieu.revest@chu-rennes.fr 
Key points: In this cohort study of 180 patients with staphylococcal prosthetic valve endocarditis, rifampin use was associated neither with better survival, nor with lower risk of relapse. Cerebral emboli, definite endocarditis, and methicillin-resistant S. aureus were independently associated with one-year mortality. 


\begin{abstract}
Background. International guidelines recommend rifampin-based combinations for staphylococcal prosthetic valve endocarditis (PVE). However, no robust clinical data supports this recommendation, and rifampin tolerability is an issue. We aimed to evaluate the impact of rifampin for the treatment of staphylococcal PVE.
\end{abstract}

Methods. An observational retrospective cohort study of all adults with staphylococcal PVE (modified Duke criteria) was conducted in three referral centers for endocarditis, during years 2000-2018. Primary outcome measurement was one-year mortality.

Results. We enrolled 180 patients with PVE due to Staphylococcus aureus ( $\mathrm{n}=114,63.3 \%$ ), or coagulase-negative staphylococci $(n=66,36.7 \%)$, on bioprosthesis $(n=111,61.7 \%)$, mechanical valve $(n=67,37.2 \%)$, or both $(n=2)$. There were 132 males $(73.3 \%)$, and mean age was $70.4 \pm 12.4$ years. Valvular surgery was performed in 51/180 (28.3\%) cases. Despite all isolates were susceptible to rifampin, only $101(56.1 \%)$ were treated with rifampin, for a median duration of 33.0 days, while 79 (43.9\%) received no rifampin. Baseline characteristics were similar in both groups. One-year mortality was, respectively, $37.6 \%$ $(38 / 101)$, and $31.6 \%(25 / 79)$, in patients treated with, or without, rifampin $(P=0.62)$. Relapse rates were $5.9 \%(6 / 101)$, and $8.9 \%$ (7/79), $P=0.65$. Patients treated with rifampin had longer hospital length-of-stay: $42.3 \pm 18.6$ vs. $31.3 \pm 14.0$ days $(P<0.0001)$. On multivariate analysis, only cerebral emboli (OR 2.95, CI95\% 1.30-6.70, $P=0.009$ ), definite endocarditis (OR 7.15, 1.47-34.77, $P=0.018$ ), and methicillin-resistant $S$. aureus (OR 6.04, 1.34-27.26, $P=0.019$ ), were associated with one-year mortality.

Conclusions. A large proportion (43.9\%) of staphylococcal PVE received no rifampin. Oneyear survival and relapse rates were similar in patients treated with or without rifampin.

Keywords. Rifampin; prosthetic valve; endocarditis; mortality; relapse 


\section{INTRODUCTION}

The profile of infective endocarditis (IE) has dramatically changed over the last decades, with the emergence of healthcare-associated IE $(1,2)$, including prosthetic valve IE (PVE). In parallel, staphylococci became the leading cause of IE in most contemporary cohorts. The prospective cohort study of the International Collaboration on Endocarditis (ICE) found that Staphylococcus aureus and coagulase-negative staphylococcus (CoNS) are responsible for, respectively, 23\% and 17\% of PVE (3). Staphylococcal PVE are associated with high one-year mortality rates, ranging from $40 \%$ to $80 \%$ (4). Hence, optimal antibacterial treatment is of paramount importance for staphylococcal PVE.

The two major international guidelines, from America and Europe, are remarkably concordant regarding antibiotic regimen to apply in patients with staphylococcal PVE. It relies on intravenous (i.v.) anti-staphylococcal penicillin or cefazolin for methicillinsusceptible staphylococci, and i.v. glycopeptides or lipopeptides for methicillin-resistant staphylococci (5), combined with i.v. gentamicin during the first two weeks, and rifampin for the whole duration of treatment, i.e. six weeks. Minor discrepancies are found regarding rifampin administration, with a recommended daily dose from 600 to $1200 \mathrm{mg}$, oral or i.v., divided in 2 or 3 intakes per day $(6,7)$, but its use is strongly encouraged, labelled as class 1 recommendation both for the American Heart Association (7), and the European Society of Cardiology (6). However, due to the absence of any randomized clinical trial supporting this position, this recommendation is only associated with a B level of evidence.

Rifampin is a rifamycin B derivative, which inhibits bacterial RNA polymerase by blocking the path of elongating RNA (8). It is believed to have a special role in prosthetic devices infection, due to its activity on planktonic bacteria embedded in biofilms, which would contribute to eradicate bacteria attached on foreign material, thereby reducing the risk 
of relapse $(5,6)$. However, experimental and clinical data on the impact of rifampin-based combinations remain limited in the field of PVE, and rifampin use has been associated with severe adverse events, including the potential for interactions with a large number of drugs (anticoagulants, antiepileptics, immunomodulators, etc.) (9). Given the poor level of evidence supporting the systematic use of rifampin-based combination for the treatment of staphylococcal PVE, we aimed to evaluate the risks and the benefits associated with rifampin use through a retrospective multicenter study of patients managed in referral centers for IE.

\section{METHODS}

\section{Design, Setting and Patients}

This observational multicenter retrospective cohort study was conducted in three referral centers for IE in western France: Brest, Nantes and Rennes (population catchment area, 7 million inhabitants). In these centers, all patients with suspected IE are managed by a multidisciplinary team including members from cardiac surgery, cardiology, infectious diseases, and microbiology departments. Most patients received medical and surgical treatment in agreement with international guidelines, i.e. the American Heart Association (AHA) guidelines until 2009, the European Society of Cardiology (ESC) guidelines from 2009 to 2015, and a combination of both since they were updated in 2015.

All adult patients ( $\geq 18$ years old) with a diagnosis of staphylococcal PVE treated from January 2000 through June 2018 in Rennes, and from January 2010 through June 2018 in Nantes and Brest, were enrolled in the study. Patients were identified using the French hospital discharge database (French acronym PMSI): All medical charts with a discharge diagnosis of IE were individually screened. In one site (Nantes), a prospective cohort study of 
all patients with IE was initiated in January 2013. Hence, for this site, patients were enrolled through this cohort between January 2013 and July 2018. Patients were included if they were classified as definite or possible IE according to the modified Duke criteria (10), due to $S$. aureus or CoNS, with the involvement of at least one prosthetic valve. The exclusion criteria were history of congenital heart disease, aortic root replacement, and transcatheter valve replacement.

\section{Data collection}

Data for clinical, microbiological, echocardiographic variables, as well as management of PVE and follow-up, were collected on a standardized questionnaire from medical charts. The data collected were entered into a database created specifically for the study by a single investigator (ALB).

\section{Ethics}

The study was approved by an institutional review board, the Ethical Committee of Research in Tropical and Infectious Diseases (CER-MIT, $\mathrm{n}^{\circ} 2019-0703$ ).

\section{Definitions}

All study definitions, outcomes, and variables were determined $a$ priori. The Charlson comorbidity index (11) was calculated retrospectively with the comorbidities reported at the time of admission. Early-PVE was defined as IE occurring within 60 days after prosthetic valve implantation (5). Healthcare-associated IE was defined as either nosocomial (IE developing in a patient hospitalized for more than 48 hours), or non-nosocomial healthcareassociated infection, as defined elsewhere (3). Intracardiac devices were permanent pacemakers or cardioverter-defibrillators. Cerebral emboli were defined as acute onset of neurological symptoms attributed to stroke and confirmed on brain imaging. Early valve 
surgery was defined as valve surgery within 60 days after the diagnosis of endocarditis (4). All patients received appropriate i.v. antibiotics, i.e. cefazolin or anti-staphylococcal penicillin (cloxacillin, oxacillin), combined with gentamicin for methicillin-susceptible staphylococci, and glycopeptides (vancomycin), or lipopeptides (daptomycin), combined with gentamicin for methicillin-resistant staphylococci, at the doses recommended in the 2015 international guidelines $(6,7)$.

\section{Outcomes}

The primary endpoint was death from any cause during the one-year follow-up. Relapse was defined as a new diagnosis of IE caused by the same microorganism as the initial PVE, within six months. Hospital length of stay was defined as the time from the first positive blood culture, to discharge. Vitamin $\mathrm{K}$ antagonists (VKA) imbalance was defined by two consecutive International Normalized Ratio (INR) $>4$ or $<1.5$ more than 7 days after treatment start. Bleeding complications were defined as hemoglobin decrease $>2 \mathrm{~g} / \mathrm{dL}$ between two measurements, or any life-threatening hemorrhage reported in the medical chart.

\section{Statistical Analysis}

We compared two mutually exclusive groups of patients: i) patients who were treated with rifampin-based combination; ii) patients who received no rifampin throughout PVE treatment. Patients were allocated to the rifampin group if they received at least one dose of rifampin. Quantitative variables were expressed as mean $+/$ - standard deviation, or as median with interquartile range $[\mathrm{IQR}]$, as appropriate. Qualitative variables were expressed by frequency and percentage. Continuous variables were compared using the Mann-Whitney test or the exact $t$-test, as appropriate. Categorical variables were compared using the $\mathrm{Chi}^{2}$ test with Yates continuity correction. Multivariate analyses were performed using exact logistic regression. Clinically relevant factors associated to outcome with $P<0.20$ in the univariate 
analysis, and variables associated with 1-year-mortality in the literature were included in the multivariate model. All tests were two-tailed, and significance was set at $P<0.05$. Statistical analyses were performed using PRISM (v5.0 for Windows, GraphPad Software, Inc., CA, USA) and STATA (v. 9.0 for Windows, Statacorp LLC, TX, USA).

\section{RESULTS}

\section{Demographics and baseline characteristics}

During the study period, 180 episodes of staphylococcal PVE were managed in the participating sites, classified as definite $(n=149)$, or possible $(n=31)$. Of them, $101(56.1 \%)$ received an antibiotic regimen with rifampin, and 79 (43.9\%) were treated without rifampin (Fig 1). They were 132 males (73.3\%), and 48 females (26.7\%), with a mean age of $70.4 \pm$ 12.4 years. PVE occurred on bioprosthesis in 111 cases $(61.7 \%)$, mechanical valves in 67 (37.2\%), and both in two (1.1\%). Cerebral emboli were reported in $53(29.4 \%)$ cases. The causative agent was S. aureus in $114(63.3 \%)$ episodes, including 17 (14.9\%) with methicillin resistance. CoNS was responsible for 66 (36.7\%) episodes, including 39 (59.0\%) with methicillin resistance. None of the 180 isolates was resistant to rifampin. Valvular surgery was performed in 51 (28.3\%) cases, most of them within 60 days after PVE diagnosis (94\%). Sixty-two patients $(34.4 \%)$ received VKA during the antibacterial treatment of their PVE. Baseline demographic, clinical and microbiological features of the 2 groups were similar, except for the proportion of S. aureus isolates resistant to methicillin, at 21.9\% (14/64) in patients treated with rifampin, vs $6.0 \%(3 / 50)$ in patients who received no rifampin, $P=0.04$ (Table 1). 


\section{Rifampin treatment}

The median duration of rifampin was 33.0 days (IQR, 12.5 - 41.2) with a median dose of $1200 \mathrm{mg}$ per day (IQR, 900 - $1200 \mathrm{mg}$ ). Median time between first positive blood culture and rifampin start was 7 days (IQR, 3 - 15 days). Rifampin had to be prematurely discontinued because of severe adverse events in 31 patients (30.7\%), mainly because of liver toxicity $(n=11)$, digestive disorders $(n=4)$, cytopenia $(n=4)$, VKA imbalance $(n=3)$, renal toxicity $(n=2)$, allergy $(n=2)$, treatment failure $(n=2)$, or not specified $(n=3)$. Of the 35 patients who were treated with VKA when rifampin was introduced, 15 (42.9\%) presented VKA imbalance during rifampin treatment or during the week following rifampin discontinuation, deemed to be related to drug interactions (Supplementary Table 1). Four episodes of drug interactions with drugs other than VKA were identified, with methadone $(n=2)$, phenytoin $(n=1)$, and mianserin $(n=1)$. None of these were responsible for rifampin discontinuation. No emergence of resistance to rifampin was observed in the six patients who relapsed with positive blood cultures.

\section{Outcome}

In-hospital mortality was $23.6 \%(42 / 180)$, and one-year mortality was $35.4 \%$ (63/180). Thirteen patients (7.3\%) relapsed. Outcomes were similar in patients treated with, or without rifampin, except for hospital length-of-stay, with a mean of 42.3 days \pm 18.6 in patients treated with rifampin $(\mathrm{n}=101)$ vs 31.3 days \pm 14.0 in patients who did not receive rifampin, $P<0.0001$ (Table 2). Results were similar when the analysis was stratified by pathogen (S. aureus and CoNS, Table 3), when it was restricted to patients with definite IE according to modified Duke classification (supplementary table 2), to patients with PVE due to methicillin-resistant staphylococci (supplementary table 3), or when it was restricted to patients who underwent no valve replacement (supplementary table 4). 
The only factor associated with one-year mortality on univariate analysis was cerebral emboli. On multivariate analysis, cerebral emboli (odds ratio 2.95, CI95\% 1.30-6.70, $P=0.009$ ), definite endocarditis according to modified Duke criteria (OR 7.15, 1.47-34.77, $P=0.018$ ), and methicillin-resistant $S$. aureus (OR 6.04, 1.34-27.26, $P=0.019$ ), were independently associated with one-year mortality (Table 4).

\section{DISCUSSION}

The major findings of this retrospective study of staphylococcal PVE managed in 3 referral centers for IE are the following: i) in spite of international guidelines, a large proportion of patients with rifampin-susceptible staphylococcal PVE are treated without rifampin $(79 / 180,43.9 \%)$; ii) baseline characteristics of patients treated with, or without rifampin, were similar; iii) rifampin use was not associated with any measurable benefit, neither for survival, nor for risk of relapse; iv) patients treated with rifampin had longer hospital length-of-stay, despite similar incidence of severe adverse events; v) the three variables independently associated with one-year mortality were cerebral emboli, definite endocarditis, and methicillin-resistant $S$. aureus PVE.

These discrepancies between international guidelines, and practices, regarding rifampin use in patients with staphylococcal PVE in three referral centers for IE, may be related to the limited clinical evidence supporting these guidelines. Pioneer studies in this field were of limited sample size, and mostly enrolled Staphylococcus epidermidis PVE $(12,13)$. More recent studies found no difference in valve sterilization rate in patients with $S$. aureus IE treated with, or without rifampin (14), and that the addition of rifampin after valvular replacement during the acute phase of staphylococcal IE was not associated with lower mortality, or decreased risk of relapse (15). A case-control study even suggested that 
rifampin use could be associated with increased mortality, and longer duration of staphylococcal bacteremia, in patients with $S$. aureus native valve IE (16). Nevertheless, beneficial effect of rifampin on another type of foreign-device infections (i.e. prosthetic joint) has been documented in a randomized trial (17). In addition, ex vivo studies and animal models have documented that rifampin is remarkable for its penetration, and bactericidal activity against dormant staphylococci within the biofilm (18-20). A recent post-hoc analysis of a large $S$. aureus bacteremia cohort suggested that antimicrobials combination, most of them containing rifampin, would be associated with reduced mortality and lower risk of late complications in patients with implanted foreign bodies (21).

The second reason why rifampin use is low in patients with staphylococcal PVE could be related to its association with adverse events, and drug interactions. Rifampin-related liver toxicity is not rare, mostly affects patients with underlying liver diseases (22), and may lead to treatment discontinuation in as much as $30 \%$ of patients $(16,17)$, as in our cohort. Moreover, rifampin is a strong inducer of cytochrome P450 3A4 expression, thereby reducing plasma concentrations of several drugs (8). In our study, most clinically significant interactions were reported with VKA, but we found no increase of thrombo-embolic events, or bleeding complications. This may be due to close monitoring of these interactions in our centers experienced with rifampin use, primarily for treatment of staphylococcal prosthetic joint infections, and tuberculosis. The third potential reason behind the reluctance to use rifampin in staphylococcal PVE rifampin could be the theoretical risk of rifampin resistance emergence, especially in case of high inoculum or inappropriate backbone antistaphylococcal regimen $(13,14)$. In PVE, some experts recommend delaying rifampin initiation after bacteremia has been cleared, to allow penetration and activity of other antibiotics into valvular vegetations before rifampin start (7). In our study, rifampin was started with a 
median delay of 7 days after first positive blood culture, and no emergence of rifampin resistance was observed.

Despite similar baseline characteristics in patients treated with $(n=101)$, or without $(=n=79)$ rifampin, rifampin use was associated neither with better survival, nor with reduced risk of relapse. This suggests that rifampin has no added value for the eradication of staphylococci from valvular prosthesis, contrarily to what experimental studies suggested. The only significant difference between patients treated with, or without rifampin, was the longer duration of hospital stay in patients treated with rifampin. This may be related to VKA imbalance, defined as INR $>4$ or $<1.5$, and documented in $42.9 \%$ of patients co-treated with VKA and rifampin in our study, as this is an indication to delay patients discharge in our practices. Drug interactions between rifampin and VKA are usually anticipated by increasing VKA dosing, under close supervision of INR. Hence, as the degree of drug interaction varies from one patient to another, the comedication may result in INR too low, or too high. This may delay patients discharge, which may be an explanation why, although we found no significant differences between patients treated with, or without, rifampin, for all outcomes criteria, the length of stay was significantly longer in patients who received rifampin $(42.3 \pm$ 18.6 days $)$, than in patients who did not receive rifampin $(31.3 \pm 14.0$ days, $\mathrm{P}<0.0001)$. Of note, although rifampin was not associated with one-year survival, we found that definite IE according to modified Duke criteria, cerebral emboli, and methicillin-resistant PVE were all independent predictors of one-year mortality, in line with previous studies in the field $(1,4,23,24)$, thus corroborating the relevance of our cohort study.

Our study has limitations. Firstly, as data were collected retrospectively, this study has potential bias, and confounding factors. However, the rate of missing data was very low, and data were collected by a single investigator (ALB), hence reducing heterogeneity. Secondly, although this study is, to our knowledge, the largest on staphylococcal PVE to date, it may 
have been underpowered to detect any beneficial effect of rifampin, especially in certain subgroups (e.g. patients with no valve replacement), due to limited sample size. This limitation is particularly relevant for the effect of rifampin on the prevention of relapse, as only 13 relapses were identified in our study. Thirdly, as this observational study was conducted in three distinct sites, over a large period (2000-2018), there may be some heterogeneity in practices. However, this study was performed in referral centers, where patients were managed by a multidisciplinary team, according to international guidelines, so that these findings may apply to most sites with similar practices. Lastly, we have no data on rifampin exposure for the patients enrolled in this study, although wide inter-individual variability has been reported with this drug. Therapeutic drug monitoring of rifampin plasma concentrations may optimize its efficacy and tolerability, by allowing tailored rifampin dosing.

In conclusion, we found that a large proportion (43.9\%) of staphylococcal PVE receive no rifampin in referral centers for IE, in spite of the strong recommendation for the use of rifampin-based combinations in international guidelines. Rifampin use was associated neither with better survival, nor with lower risk of relapse. These findings advocate for a randomized controlled trial to evaluate the impact of rifampin use for the treatment of staphylococcal PVE. Meanwhile, our study suggests that patients with staphylococcal PVE may be reasonably treated without rifampin in case of contra-indication, or poor tolerability. 
FUNDING. No funding was received for this study

CONFLICT OF INTEREST. All none

ACKNOWLEDGEMENTS. We thank all the staff who take care of the patients. 


\section{REFERENCES}

1. Duval X, Delahaye F, Alla F, Tattevin P, Obadia J-F, Le Moing V, et al. Temporal trends in infective endocarditis in the context of prophylaxis guideline modifications: three successive population-based surveys. J Am Coll Cardiol 2012;59(22):1968- 76.

2. Fowler VG, Miro JM, Hoen B, Cabell CH, Abrutyn E, Rubinstein E, et al. Staphylococcus aureus endocarditis: a consequence of medical progress. JAMA 2005;293(24):3012- 21.

3. Wang A, Athan E, Pappas PA, Fowler VG, Olaison L, Paré C, et al. Contemporary clinical profile and outcome of prosthetic valve endocarditis. JAMA 2007;297(12):1354- 61.

4. Chirouze C, Cabell CH, Fowler VG, Khayat N, Olaison L, Miro JM, et al. Prognostic factors in 61 cases of Staphylococcus aureus prosthetic valve infective endocarditis from the International Collaboration on Endocarditis merged database. Clin Infect Dis 2004;38(9):1323- 7.

5. Saeed K, Bal AM, Gould IM, David MZ, Dryden M, Giannitsioti E, et al. An update on Staphylococcus aureus infective endocarditis from the International Society of Antimicrobial Chemotherapy (ISAC). Int J Antimicrob Agents 2019;53(1):9- 15.

6. Habib G, Lancellotti P, Antunes MJ, Bongiorni MG, Casalta J-P, Del Zotti F, et al. 2015 ESC Guidelines for the management of infective endocarditis: The Task Force for the Management of Infective Endocarditis of the European Society of Cardiology (ESC). Endorsed by: European Association for Cardio-Thoracic Surgery (EACTS), the European Association of Nuclear Medicine (EANM). Eur Heart J 2015;36(44):3075- 128.

7. Baddour LM, Wilson WR, Bayer AS, Fowler VG, Tleyjeh IM, Rybak MJ, et al. Infective Endocarditis in Adults: Diagnosis, Antimicrobial Therapy, and Management of Complications: A Scientific Statement for Healthcare Professionals From the American Heart Association. Circulation 2015;132(15):1435- 86.

8. Niemi M, Backman JT, Fromm MF, Neuvonen PJ, Kivistö KT. Pharmacokinetic interactions with rifampicin : clinical relevance. Clin Pharmacokinet. 2003;42(9):819- 50.

9. Thwaites GE, Scarborough M, Szubert A, Nsutebu E, Tilley R, Greig J, et al. Adjunctive rifampicin for Staphylococcus aureus bacteraemia (ARREST): a multicentre, randomised, doubleblind, placebo-controlled trial. Lancet 2018;391(10121):668- 78.

10. Li JS, Sexton DJ, Mick N, Nettles R, Fowler VG, Ryan T, et al. Proposed modifications to the Duke criteria for the diagnosis of infective endocarditis. Clin Infect Dis 2000;30(4):633- 8.

11. Charlson ME, Pompei P, Ales KL, MacKenzie CR. A new method of classifying prognostic comorbidity in longitudinal studies: development and validation. J Chronic Dis 1987;40(5):373- 83.

12. Karchmer AW, Archer GL, Dismukes WE. Staphylococcus epidermidis causing prosthetic valve endocarditis: microbiologic and clinical observations as guides to therapy. Ann Intern Med 1983;98(4):447- 55.

13. Karchmer AW, Archer GL, Dismukes WE. Rifampin treatment of prosthetic valve endocarditis due to Staphylococcus epidermidis. Rev Infect Dis 1983;5 Suppl 3:S543-548. 
14. Drinković D, Morris AJ, Pottumarthy S, MacCulloch D, West T. Bacteriological outcome of combination versus single-agent treatment for staphylococcal endocarditis. J Antimicrob Chemother 2003;52(5):820- 5 .

15. Shrestha NK, Shah SY, Wang H, Hussain ST, Pettersson GB, Nowacki AS, et al. Rifampin for Surgically Treated Staphylococcal Infective Endocarditis: A Propensity Score-Adjusted Cohort Study. Ann Thorac Surg 2016;101(6):2243- 50.

16. Riedel DJ, Weekes E, Forrest GN. Addition of rifampin to standard therapy for treatment of native valve infective endocarditis caused by Staphylococcus aureus. Antimicrob Agents Chemother 2008;52(7):2463- 7 .

17. Zimmerli W, Widmer AF, Blatter M, Frei R, Ochsner PE. Role of rifampin for treatment of orthopedic implant-related staphylococcal infections: a randomized controlled trial. Foreign-Body Infection (FBI) Study Group. JAMA 1998;279(19):1537- 41.

18. Zheng Z, Stewart PS. Penetration of rifampin through Staphylococcus epidermidis biofilms. Antimicrob Agents Chemother 2002;46(3):900- 3.

19. Saginur R, Stdenis M, Ferris W, Aaron SD, Chan F, Lee C, et al. Multiple combination bactericidal testing of staphylococcal biofilms from implant-associated infections. Antimicrob Agents Chemother 2006;50(1):55- 61 .

20. Revest M, Jacqueline C, Boudjemaa R, Caillon J, Le Mabecque V, Breteche A, et al. New in vitro and in vivo models to evaluate antibiotic efficacy in Staphylococcus aureus prosthetic vascular graft infection. J Antimicrob Chemother 2016;71(5):1291- 9.

21. Rieg S, Joost I, Weiß V, Peyerl-Hoffmann G, Schneider C, Hellmich M, et al. Combination antimicrobial therapy in patients with Staphylococcus aureus bacteraemia-a post hoc analysis in 964 prospectively evaluated patients. Clin Microbiol Infect 2017;23(6):406.e1-406.e8.

22. Galar A, Weil AA, Dudzinski DM, Muñoz P, Siedner MJ. Methicillin-Resistant Staphylococcus aureus Prosthetic Valve Endocarditis: Pathophysiology, Epidemiology, Clinical Presentation, Diagnosis, and Management. Clin Microbiol Rev 2019;32(2):e00041-18, /cmr/32/2/CMR.00041-18.atom.

23. Park LP, Chu VH, Peterson G, Skoutelis A, Lejko-Zupa T, Bouza E, et al. Validated Risk Score for Predicting 6-Month Mortality in Infective Endocarditis. J Am Heart Assoc 2016;5(4):e003016.

24. Fauchier L, Pericart L, Bourguignon T, Genet T, Bisson A, Bernard A, et al. Comparison of Outcome of Possible Versus Definite Infective Endocarditis Involving Prosthetic or Bioprosthetic Heart Valves. Am J Cardiol 2017 ;120(10) :1884-90. 
Table 1. Characteristics of 180 cases of staphylococcal prosthetic valve endocarditis treated with, or without, rifampin

\begin{tabular}{|c|c|c|c|c|}
\hline Variable & $\begin{array}{c}\text { Total } \\
(\mathrm{n}=180)\end{array}$ & $\begin{array}{c}\text { Rifampin-based } \\
\text { combination } \\
(\mathrm{n}=101)\end{array}$ & $\begin{array}{c}\text { No rifampin } \\
(n=79)\end{array}$ & $P$ Value \\
\hline \multicolumn{5}{|l|}{ Demographic features } \\
\hline Age, years & $70.4 \pm 12.4$ & $69.0 \pm 12.8$ & $72.2 \pm 11.6$ & .08 \\
\hline Gender, male & $132(73.3)$ & $74(73.3)$ & $58(73.4)$ & .88 \\
\hline Charlson comorbidity index & $4.7 \pm 2.3$ & $4.7 \pm 2.4$ & $4.5 \pm 2.2$ & .56 \\
\hline Intravenous drug user & $5(2.8)$ & $4(4.0)$ & $1(1.3)$ & .53 \\
\hline Cirrhosis & $9(5.0)$ & $4(4.0)$ & $5(6.3)$ & .70 \\
\hline Healthcare-associated infection & $108(60.0)$ & $57(56.4)$ & $51(64.6)$ & .34 \\
\hline \multicolumn{5}{|l|}{ Clinical features } \\
\hline Definite endocarditis (modified Duke) & $149(82.8)$ & $88(87.1)$ & $61(77.2)$ & .12 \\
\hline \multicolumn{5}{|l|}{ Type of prosthetic valve } \\
\hline Bioprosthesis & $111(61.7)$ & $60(59.4)$ & $51(64.6)$ & .58 \\
\hline Mechanical prosthesis & $67(37.2)$ & $41(40.6)$ & $26(32.9)$ & .37 \\
\hline Both & $2(1.1)$ & $0(0)$ & $2(2.5)$ & .37 \\
\hline \multicolumn{5}{|c|}{ Prosthetic valve endocarditis location } \\
\hline Aortic & $138(76.7)$ & $78(77.2)$ & $60(75.9)$ & .98 \\
\hline Mitral & $25(13.9)$ & $14(13.9)$ & $11(13.9)$ & .84 \\
\hline Tricuspid & $3(1.7)$ & $2(2.0)$ & $1(1.3)$ & .82 \\
\hline Pulmonary & $1(0.6)$ & $1(1.0)$ & $0(0)$ & .90 \\
\hline Multiple & $13(7.2)$ & $6(5.9)$ & $7(8.9)$ & .65 \\
\hline $\begin{array}{l}\text { Interval between prosthetic valve } \\
\text { implantation and endocarditis, months }\end{array}$ & $32(4-104.5]$ & $39[8-117.5]$ & $24[1-98]$ & .16 \\
\hline Early prosthetic valve endocarditis* & $34(18.9)$ & $14(13.9)$ & $20(25.3)$ & .08 \\
\hline Intracardiac device & $38(21.1)$ & $19(18.8)$ & $19(24.0)$ & .50 \\
\hline Osteoarticular infection & $18(10.0)$ & $8(7.9)$ & $10(12.7)$ & .42 \\
\hline Cerebral emboli & $53(29.4)$ & $35(34.7)$ & $18(28.8)$ & .12 \\
\hline \multicolumn{5}{|l|}{ Microbiological features } \\
\hline \multicolumn{5}{|l|}{ Staphylococcus species } \\
\hline Staphylococcus aureus & $114(63.3)$ & $64(63.4)$ & $50(63.3)$ & .88 \\
\hline Coagulase-negative staphylococci & $66(36.7)$ & $37(36.6)$ & $29(36.7)$ & .88 \\
\hline \multicolumn{5}{|l|}{ Methicillin resistance } \\
\hline Staphylococcus aureus & $17(14.9)$ & $14(21.9)$ & $3(6.0)$ & .04 \\
\hline Coagulase-negative staphylococci & $39(59.0)$ & $24(64.9)$ & $15(51.7)$ & .41 \\
\hline Rifampin resistance & $0(0)$ & $0(0)$ & $0(0)$ & \\
\hline Duration of bacteremia, days & $5.5 \pm 3.0$ & $5.6 \pm 3.6$ & $5.5 \pm 3.5$ & .98 \\
\hline Positive valve culture if surgery & $11(22)$ & $5(15.6)$ & $6(33.3)$ & .19 \\
\hline
\end{tabular}




\begin{tabular}{|lcccc|}
\hline Treatment & $51(28.3)$ & $34(33.7)$ & $17(21.5)$ & .10 \\
\hline Valve surgery & $48(94)$ & $32(94.1)$ & $16(94.1)$ & .53 \\
\hline \multicolumn{1}{|c}{$\begin{array}{l}\text { Early valve surgery } \\
\quad \text { Interval between first positive blood } \\
\quad \text { culture and surgery, days }\end{array}$} & $13[8-20.2]$ & $14.0[11-19.5]$ & $10.0[5-17]$ & .23 \\
\hline $\begin{array}{l}\text { Osteoarticular surgery } \\
\text { Lifelong suppressive antibacterial }\end{array}$ & $5(27.8)$ & $3(37.5)$ & $2(20.0)$ & .77 \\
treatment & $7(3.9)$ & $2(2.0)$ & $5(6.3)$ & .27 \\
\hline Vitamin K antagonists & $62(34.4)$ & $35(34.7)$ & $27(34.2)$ & .93 \\
\hline Heparin & $83(46.1)$ & $52(51.5)$ & $31(39.2)$ & .14 \\
\hline
\end{tabular}

Quantitative variables are expressed as mean $+/$ - standard deviation or median (IQR), qualitative variables are expressed by numbers $(\%)$ * time between valve implantation, and endocarditis, $<60$ days; ${ }^{\$}$ Cardiac surgery within 60 days after endocarditis diagnosis 
Table 2. Outcomes of 180 episodes of staphylococcal prosthetic valve endocarditis treated with, or without, rifampin

\begin{tabular}{lccccc}
\hline Variable & Total & $\begin{array}{c}\text { Rifampin-based } \\
\text { combination } \\
(\mathrm{n}=101)\end{array}$ & $\begin{array}{c}\text { No rifampin } \\
(\mathrm{n}=79)\end{array}$ & $\begin{array}{c}\text { Odd-Ratio (CI } \\
\mathbf{9 5 \%})\end{array}$ & $\boldsymbol{P}$ Value \\
\hline Mortality & $(\mathrm{n}=180)$ & $26(25.7)$ & $16(20.3)$ & $1.4(0.67-2.77)$ & .49 \\
$\quad$ In-hospital mortality & $42(23.6)$ & $36(35.6)$ & $22(27.8)$ & $1.4(0.76-2.72)$ & .34 \\
$\quad$ Six-month mortality & $58(32.6)$ & $38(37.6)$ & $25(31.6)$ & $1.2(0.66-2.28)$ & .62 \\
$\quad$ One-year mortality & $63(35.4)$ & $6(5.9)$ & $7(8.9)$ & $0.64(0.21-2.02)$ & .65 \\
\hline Relapse & $13(7.3)$ & $15(42.9)$ & $6(22.2)$ & $2.63(0.85-8.11)$ & .15 \\
\hline $\begin{array}{l}\text { Vitamin K antagonist imbalance } \\
\text { during endocarditis }\end{array}$ & $21(33.9)$ & $13(12.8)$ & $10(12.7)$ & $1.02(0.42-2.46)$ & .85 \\
\hline $\begin{array}{l}\text { Bleeding complication } \\
\text { Length of stay, days }\end{array}$ & $23(12.9)$ & $42.3 \pm 18.6$ & $31.3 \pm 14.0$ & - & $<.0001$ \\
\hline
\end{tabular}

Quantitative variables are expressed as mean $+/$ - standard deviation, qualitative variables are expressed by numbers (\%) 
Table 3. Outcome of prosthetic valve endocarditis due to Staphylococcus aureus $(n=114)$, and or coagulase-negative staphylococci $(n=66)$ in patients treated with, or without, rifampin

\begin{tabular}{|c|c|c|c|c|c|c|c|c|}
\hline \multirow[t]{2}{*}{ Variable } & \multicolumn{4}{|c|}{$\begin{array}{c}\text { Staphylococcus aureus } \\
(\mathrm{n}=114)\end{array}$} & \multicolumn{4}{|c|}{$\begin{array}{l}\text { Coagulase negative staphylococci } \\
\qquad(n=66)\end{array}$} \\
\hline & $\begin{array}{c}\text { Rifampin- } \\
\text { based } \\
(\mathrm{n}=64)\end{array}$ & $\begin{array}{c}\text { No } \\
\text { rifampin } \\
(\mathrm{n}=50)\end{array}$ & $\begin{array}{c}\text { Odd- } \\
\text { Ratio } \\
(\mathrm{CI} \\
95 \%)\end{array}$ & $\begin{array}{c}P \\
\text { Value }\end{array}$ & $\begin{array}{c}\text { Rifampin- } \\
\text { based } \\
(\mathrm{n}=37)\end{array}$ & $\begin{array}{c}\text { No } \\
\text { rifampin } \\
(n=29)\end{array}$ & $\begin{array}{c}\text { Odd- } \\
\text { Ratio } \\
(\text { CI } \\
95 \%)\end{array}$ & $\begin{array}{c}P \\
\text { Value }\end{array}$ \\
\hline \multicolumn{9}{|l|}{ Mortality } \\
\hline $\begin{array}{l}\text { In-hospital } \\
\text { mortality }\end{array}$ & $18(28.1)$ & $12(24.0)$ & $\begin{array}{c}1.24 \\
(0.53- \\
2.89)\end{array}$ & .78 & 8 (21.6) & $4(13.8)$ & $\begin{array}{c}1.72 \\
(0.46- \\
6.41)\end{array}$ & .61 \\
\hline $\begin{array}{l}\text { Six-month } \\
\text { mortality }\end{array}$ & $26(40.6)$ & $16(32.0)$ & $\begin{array}{c}1.45 \\
(0.66- \\
3.16)\end{array}$ & .45 & $10(27.0)$ & $6(20.7)$ & $\begin{array}{c}1.42 \\
(0.45- \\
4.50)\end{array}$ & .76 \\
\hline $\begin{array}{l}\text { One-year } \\
\text { mortality }\end{array}$ & $27(42.2)$ & $18(36.0)$ & $\begin{array}{c}1.30 \\
(0.61- \\
2.78)\end{array}$ & .63 & $11(29.7)$ & $7(24.1)$ & $\begin{array}{c}1.33 \\
(0.44- \\
4.01)\end{array}$ & .82 \\
\hline Relapse & $4(6.3)$ & $4(8.0)$ & $\begin{array}{c}0.93 \\
(0.22- \\
3.91)\end{array}$ & .79 & $2(5.4)$ & $3(10.3)$ & $\begin{array}{c}0.49 \\
(0.08- \\
3.18)\end{array}$ & .78 \\
\hline $\begin{array}{l}\text { Vitamin K } \\
\text { antagonist } \\
\text { imbalance }\end{array}$ & $9(39.1)$ & $4(22.2)$ & $\begin{array}{c}2.25 \\
(0.56- \\
9.05)\end{array}$ & .41 & $6(50.0)$ & $2(22.2)$ & $\begin{array}{c}3.5 \\
(0.50- \\
24.3)\end{array}$ & .40 \\
\hline $\begin{array}{l}\text { Bleeding } \\
\text { complication }\end{array}$ & $10(15.6)$ & $10(20.0)$ & $\begin{array}{c}0.72 \\
(0.28- \\
1.95)\end{array}$ & .71 & $3(8.1)$ & $0(0)$ & $\begin{array}{c}5.99 \\
(0.29- \\
120.8)\end{array}$ & .33 \\
\hline $\begin{array}{l}\text { Length of stay, } \\
\text { days }\end{array}$ & $42.8 \pm 20.1$ & $30.7 \pm 14.7$ & - & .0006 & $41.4 \pm 16.1$ & $32.4 \pm 12.9$ & - & .02 \\
\hline
\end{tabular}

Quantitative variables are expressed as mean $+/$ - standard deviation, qualitative variables are expressed by numbers $(\%)$ 
Table 4. Univariate and multivariate analysis of variables associated with one-year mortality

\begin{tabular}{|c|c|c|c|c|c|c|}
\hline \multirow[b]{2}{*}{ Variable } & \multicolumn{3}{|c|}{ Univariate } & \multirow[b]{2}{*}{$P$ Value } & \multicolumn{2}{|c|}{ Multivariate } \\
\hline & $\begin{array}{l}\text { Dead during the 1-year } \\
\text { follow-up } \\
\text { (n=63) }\end{array}$ & $\begin{array}{l}\text { Alive at 1-year } \\
\qquad(n=117)\end{array}$ & Odd-Ratio (Cl 95\%) & & Odd-Ratio (Cl 95\%) & $P$ Value \\
\hline Age, per one year increment & $70.6 \pm 13.2$ & $70.3 \pm 11.9$ & & .73 & $0.98(0.94-1.02)$ & .45 \\
\hline Gender, male & $45(71.4)$ & $87(74.4)$ & $0.86(0.43-1.71)$ & .80 & & \\
\hline Charlson comorbidity index, per one point increment & $5.1 \pm 2.6$ & $4.5 \pm 2.1$ & & .12 & $1.14(0.91-1.44)$ & .24 \\
\hline Healthcare-associated infection & 35 (56.6) & $73(64.0)$ & $0.72(0.39-1.37)$ & .41 & & \\
\hline Definite endocarditis (modified Duke criteria) & $57(90.5)$ & $92(78.6)$ & $2.38(0.91-6.19)$ & .11 & $7.15(1.47-34.77)$ & .018 \\
\hline Bioprosthesis & $38(60.3)$ & $75(64.1)$ & $0.85(0.45-1.60)$ & .73 & & \\
\hline Mechanical prosthesis & $25(39.7)$ & $43(36.8)$ & $1.16(0.62-2.19)$ & .76 & & \\
\hline Aortic location & $44(69.8)$ & $94(80.3)$ & $0.57(0.28-1.15)$ & .16 & $0.79(0.25-2.46)$ & .68 \\
\hline Mitral location & $8(12.7)$ & $17(14.5)$ & $0.86(0.36-2.11)$ & .91 & & \\
\hline $\begin{array}{l}\text { Interval between prior cardiac surgery and } \\
\text { endocarditis }\end{array}$ & $31(4-119)$ & $35(3-103)$ & & .87 & $0.90(0.62-1.29)$ & .56 \\
\hline Intracardiac device & $11(17.5)$ & $27(23.1)$ & $0.71(0.32-1.54)$ & .49 & & \\
\hline Cerebral emboli & 27 (42.9) & $26(22.2)$ & $2.62(1.35-5.10)$ & .006 & $2.95(1.30-6.70)$ & .009 \\
\hline Staphylococcus aureus & $45(71.4)$ & $69(59.0)$ & $1.74(0.90-3.36)$ & .14 & & \\
\hline Methicillin-resistant S. aureus & $9(14.3)$ & $8(6.8)$ & $2.27(0.83-6.22)$ & .17 & $6.04(1.34-27.26)$ & .019 \\
\hline Methicillin-resistant coagulase-negative staphylococci & $13(20.6)$ & $26(22.2)$ & $0.91(0.43-1.93)$ & .95 & & \\
\hline Duration of bacteremia & $5.8 \pm 3.3$ & $5.4 \pm 3.7$ & & .37 & $0.88(0.24-3.24)$ & .85 \\
\hline Valve surgery & $14(22.2)$ & $36(30.8)$ & $0.64(0.32-1.31)$ & .30 & $0.60(0.24-1.52)$ & .29 \\
\hline Vitamin $\mathrm{K}$ antagonist during endocarditis treatment & $17(27.0)$ & 45 (38.5) & $0.59(0.30-1.16)$ & .16 & $0.63(0.26-1.56)$ & .32 \\
\hline Bleeding complication & $6(9.5)$ & $12(10.3)$ & $0.92(0.33-2.59)$ & .92 & & \\
\hline Rifampin treatment & $38(60.3)$ & $63(53.8)$ & $1.30(0.70-2.42)$ & .50 & $0.90(0.38-2.11)$ & .81 \\
\hline
\end{tabular}


Figure 1. Flow diagram of patients enrollment

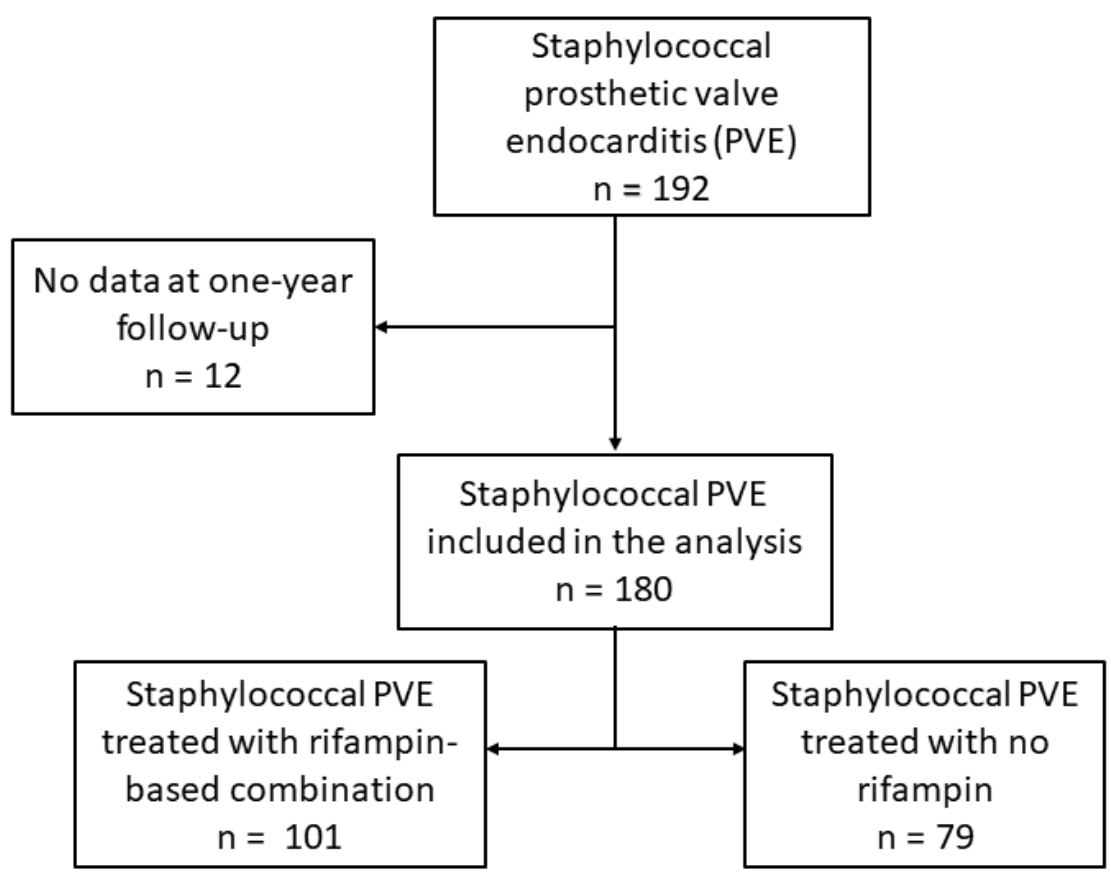

